ARTICLE

https://doi.org/10.1038/s41467-021-24453-6

\title{
Detection of high-valent iron species in alloyed oxidic cobaltates for catalysing the oxygen evolution reaction
}

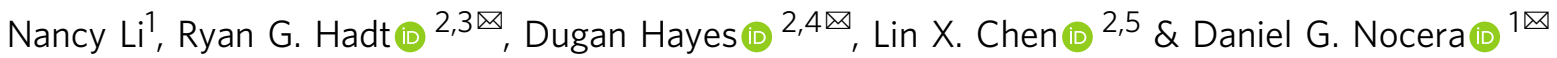

Iron alloying of oxidic cobaltate catalysts results in catalytic activity for oxygen evolution on par with $\mathrm{Ni}$-Fe oxides in base but at much higher alloying compositions. Zero-field ${ }^{57} \mathrm{Fe}$ Mössbauer spectroscopy and X-ray absorption spectroscopy (XAS) are able to clearly identify $\mathrm{Fe}^{4+}$ in mixed-metal $\mathrm{Co}-\mathrm{Fe}$ oxides. The highest $\mathrm{Fe}^{4+}$ population is obtained in the $40-60 \%$ Fe alloying range, and XAS identifies the ion residing in an octahedral oxide ligand field. The oxygen evolution reaction (OER) activity, as reflected in Tafel analysis of $\mathrm{CoFeO}_{x}$ films in $1 \mathrm{M} \mathrm{KOH}$, tracks the absolute concentration of $\mathrm{Fe}^{4+}$. The results reported herein suggest an important role for the formation of the $\mathrm{Fe}^{4+}$ redox state in activating cobaltate OER catalysts at high iron loadings.

\footnotetext{
${ }^{1}$ Department of Chemistry and Chemical Biology, Harvard University, Cambridge, MA, USA. ${ }^{2}$ Chemical Sciences and Engineering Division, Argonne National Laboratory, Lemont, IL, USA. ${ }^{3}$ Division of Chemistry and Chemical Engineering, California Institute of Technology, Pasadena, CA, USA. ${ }^{4}$ Department of Chemistry, University of Rhode Island, Kingston, RI, USA. ${ }^{5}$ Department of Chemistry, Northwestern University, Evanston, IL, USA. ${ }^{凶}$ email: rghadt@caltech.edu; dugan@uri.edu; dnocera@fas.harvard.edu
} 
$\mathrm{D}$ imensional reduction of first row metal oxides gives rise to metallate oxygen evolving catalysts (M-OECs) that exhibit high activity for the oxygen evolution reaction $(\mathrm{OER})^{1-5}$. Electrodeposition of oxidic cobaltates and nickelates in the presence of phosphate and borate $\left(\mathrm{CoP}_{i}{ }^{6,7}, \mathrm{CoB}_{\mathrm{i}}^{8,9}, \mathrm{NiB}_{\mathrm{i}}{ }^{10,11}\right.$, $\mathrm{MnP}_{\mathrm{i}}{ }^{12,13}$ ) results in clusters of $10-60$ metal atoms, as determined from in situ pair distribution functional analysis ${ }^{9,14-19}$. The selfhealing property of the M-OECs ${ }^{2,20-22}$ allows them to promote water-splitting under benign conditions. Under such conditions, the catalysts may be easily interfaced with materials for direct conversion of water to oxygen and hydrogen at high efficiency $^{23-26}$, as well as interfaced with biological organisms to perform artificial photosynthesis ${ }^{27}$ at efficiencies greatly exceeding natural photosynthesis ${ }^{28,29}$. The metallate clusters possess a high edge-to-area ratio that engenders high activity, as revealed by isotopic labelling studies ${ }^{30}$ that show the critical $\mathrm{O}-\mathrm{O}$ bond formation step to occur by proton-coupled electron transfer (PCET) at cluster edge sites ${ }^{8,31-36}$. Moreover, the electronic charge in M-OECs can delocalize within the clusters ${ }^{37,38}$ giving rise to electron/hole transport ${ }^{39}$ that can maximally couple to the ion transport needed to support the OER ${ }^{40,41}$.

Iron doping of metal oxide films has long been known to increase overall OER activity of metal oxide OER catalysts ${ }^{42,43}$. The behaviour of $\mathrm{Fe}$ in Ni-OECs has been revisited ${ }^{44}$, and the role of $\mathrm{Fe}$ has been ascribed to various factors, including active site $\mathrm{Fe}^{4}$ + or higher valent species ${ }^{45-47}$, near neighbour Fe effects on $\mathrm{Ni}$ resulting from strain on the oxide lattice ${ }^{48-51}$, active oxygen intermediates at $\mathrm{Ni}-\mathrm{Fe}$ sites $^{52-54}$, Fe induced partial-chargetransfer to Ni sites ${ }^{55,56}$, and $\mathrm{Fe}$ acting as a Lewis acid that promotes charge transfer character and favourable energetics for $\mathrm{Ni}$ oxyl formation ${ }^{57,58}$. Quizzically, though detected by Mössbauer spectroscopy, the presence of $\mathrm{Fe}^{4+}$ does not correlate with the observed catalytic activity ${ }^{59}$. Iron loading has also been shown to affect the OER activity of Co-OECs $s^{60-62}$, but at very different alloying loads. Whereas Ni-OECs show maximal activity with $\mathrm{Fe}$ loadings of $\sim 5 \mathrm{~mol} \% \mathrm{Fe}^{42,55}$, the maximal activity of Co-OECs is observed for Fe loadings of $>40 \mathrm{~mol} \% \mathrm{Fe}^{61}$. These higher loadings suggest different roles for $\mathrm{Fe}$ in enhancing M-OEC activity at high versus low alloying.

We now report the zero-field ${ }^{57} \mathrm{Fe}$ Mössbauer and X-ray absorption spectroscopy (XAS) of Co-OEC alloyed with Fe from 0 to $100 \%$ and show that, unlike Fe alloyed in Ni-OECs, the

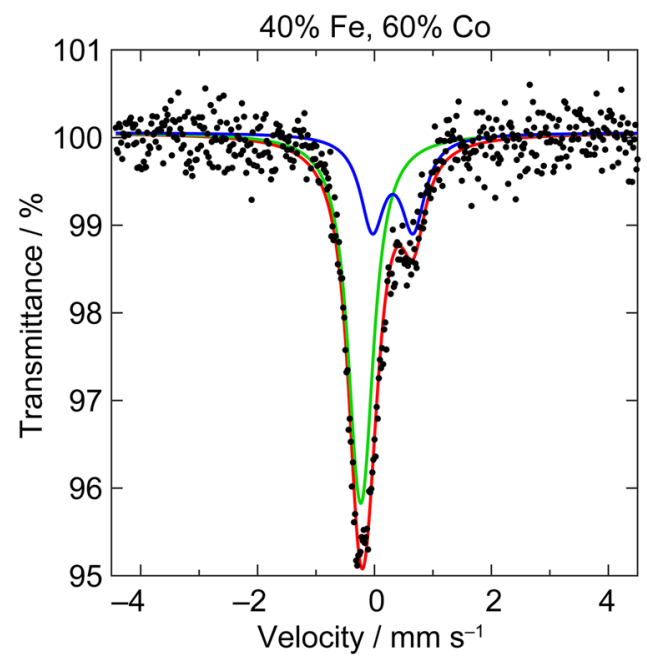

Fig. 1 Mössbauer spectra of $\mathbf{C o F e O}_{\mathbf{x}}$. Zero-field ${ }^{57} \mathrm{Fe}$ Mössbauer spectra for $\mathrm{CoFeO}_{x}$ films with the composition $40 \% \mathrm{Fe}: 60 \% \mathrm{Co}$. Raw data (black circle), fit for $\mathrm{Fe}^{3+}$ species (blue line), $\mathrm{Fe}^{4+}$ species (green line), and overall fit (red line). presence of $\mathrm{Fe}^{4+}$ tracks OER activity, suggesting that $\mathrm{Fe}^{4+}$ is intimately involved as a redox activator of OER. The results suggest different roles for Fe in alloyed M-OEC catalysts. At low loadings such as in (Ni:Fe)-OECs, OER is performed by $\mathrm{Ni}$ active sites and Fe promotes the PCET activation of OER. At high loadings, as is observed here for Fe-alloyed Co-OEC catalysts, the redox properties of $\mathrm{Fe}$ appear to play a prominent and more direct role in promoting OER.

\section{Results}

A series of $\mathrm{CoFeO}_{x}$ films with varying Fe content were prepared by cathodic deposition upon the reduction of nitrate to induce a high local basic $\mathrm{pH}$ near the electrode, resulting in the electrodeposition of a Co:Fe hydroxide film ${ }^{13}$, which was then converted to $\mathrm{CoFeO}_{x}$ with the application of an anodic potential. Metal elemental compositions were determined by inductively coupled mass spectrometry (ICP-MS) of digested films after electrochemical measurements. Previous studies have shown that Fe and Co deposit homogeneously as detected by SEM/EDS analysis ${ }^{63}$. As $\mathrm{Fe}$ content increases, both the cathodic and anodic features of the $\mathrm{Co}^{2+/ 3+}$ couple are shifted towards higher potentials (Supplementary Fig. 1). $\mathrm{CoFeO}_{x}$ films with $40-80 \mathrm{~mol} \% \mathrm{Fe}$ in $1 \mathrm{M}$ $\mathrm{KOH}$ that was scrubbed of trace metal contaminants display Tafel slopes of $\sim 30 \mathrm{mV} / \mathrm{dec}$ (Supplementary Fig. 2), similar to previously published results ${ }^{61}$. We note that the lowest Tafel slopes in $\mathrm{CoFeO}_{x}$ films are obtained at much higher Fe:Co ratios than observed for $\mathrm{NiFeO}_{x}$ films.

The electronic structure of $\mathrm{Fe}$ centres in $\mathrm{CoFeO}_{x}$ films was probed with zero-field ${ }^{57} \mathrm{Fe}$ Mössbauer spectroscopy. A representative ${ }^{57} \mathrm{Fe}$ Mössbauer spectrum is given in Fig. 1; the spectra of all $\mathrm{CoFeO}_{x}$ film samples are given in Supplementary Fig. 3 and Supplementary Fig. 4. The spectra are reproducible and sensitive to $\mathrm{Fe}$ population changes between samples with $10 \mathrm{~mol} \% \mathrm{Fe}$ differences (Supplementary Fig. 5). Two species of Fe are detected in the ${ }^{57} \mathrm{Fe}$ Mössbauer spectra. Fits of the spectra furnish corresponding isomer shifts $(\delta)$ and quadrupole splittings $\left(\left|\Delta E_{\mathrm{Q}}\right|\right)$ for one species with $\delta \sim 0.3 \mathrm{~mm} / \mathrm{s}$ and $\left|\Delta E_{\mathrm{O}}\right| \sim 0.7 \mathrm{~mm} / \mathrm{s}$ and the other species with $\delta \sim-0.2 \mathrm{~mm} / \mathrm{s}$ and $\left|\Delta E_{\mathrm{Q}}\right|$ less than the resolved linewidth $(\sim 0.3 \mathrm{~mm} / \mathrm{s})$. These values, which are somewhat sensitive to total $\mathrm{Fe}$ alloying concentrations and fittings (Supplementary Fig. 7), do not correspond to either $\mathrm{Fe}_{2} \mathrm{O}_{3}{ }^{64,65}$ or metallic $\mathrm{Fe}^{66,67}$. One species matches the Mössbauer parameters of high spin (HS) $\mathrm{Fe}^{3+}$ in the oxide ligand field of $\mathrm{NiFeO}_{x}^{5,68,69}$ and $\mathrm{FeOOH}^{70}$. The Mössbauer parameters of the second $\mathrm{Fe}$ species correspond to those observed previously for $\mathrm{Fe}^{4+}$ in $\mathrm{NiFeO}_{x}{ }^{70}$, and is consistent with theoretical calculations showing the persistence of $\mathrm{Fe}^{4+}$ in $\mathrm{NiFeO}_{x}{ }^{71}$. The $\mathrm{Fe}^{3+}: \mathrm{Fe}^{4+}$ ratio, which may be determined from the Mössbauer parameters, shifts towards $\mathrm{Fe}^{3+}$ at low and high Fe concentrations (Supplementary Fig. 6) with a maximal absolute $\mathrm{Fe}^{4+}$ concentration observed between 40 and $60 \%$ Fe loading (Fig. 2). Strikingly, as Fig. 2 illustrates, the population of $\mathrm{Fe}^{4+}$ in $\mathrm{CoFeO}_{x}$ films tracks OER activity as reflected in Tafel slopes. We observe a direct correlation between absolute $\mathrm{Fe}^{4+}$ content and low Tafel slopes $(30 \mathrm{mV} /$ dec), implicating the important role of $\mathrm{Fe}^{4+}$ in enhancing OER activity in $\mathrm{CoFeO}_{x}$ films at high $\mathrm{Fe}$ alloying concentrations. The maximum in activity is likely a result of $\mathrm{Fe}$ becoming the dominant compositional metal. Unary Fe oxide films are inferior OER catalysts even as ultrathin sub-monolayer films ${ }^{72}$. Thus the observed maximum in activity is consistent with the active site for OER becoming dominated by an Fe-only composition at high iron loadings in excess of $50 \%$ loading.

The assignment of $\mathrm{Fe}^{3+}$ and $\mathrm{Fe}^{4+}$ as deduced by Mössbauer spectroscopy is supported by Fe K-edge XAS of $\mathrm{CoFeO}_{x}$ samples with varying $\mathrm{Fe}$ content. The $\mathrm{X}$-ray absorption near edge 


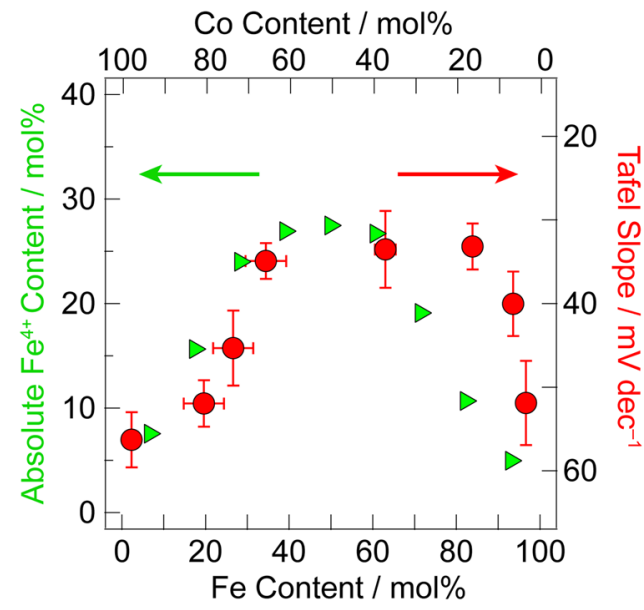

Fig. 2 Correlation of Tafel slope with $\mathbf{F e}^{\mathbf{4}+}$ composition. Overlay of Tafel slope (red circle) with absolute $\mathrm{Fe}^{4+}$ (green triangle) population in $\mathrm{CoFeO}_{x}$ films with increasing Fe content. Tafel measurements were run in triplicate, and the average value is shown on the graph at $95 \%$ confidence limits.

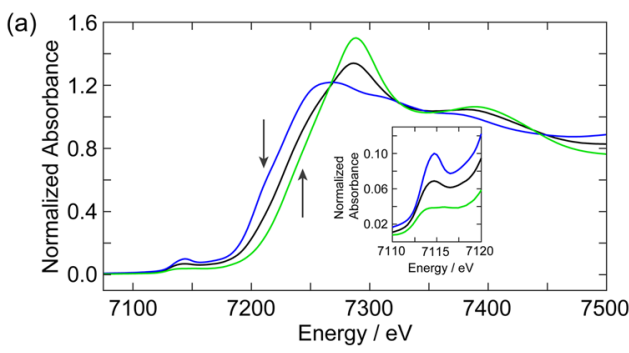

(b)

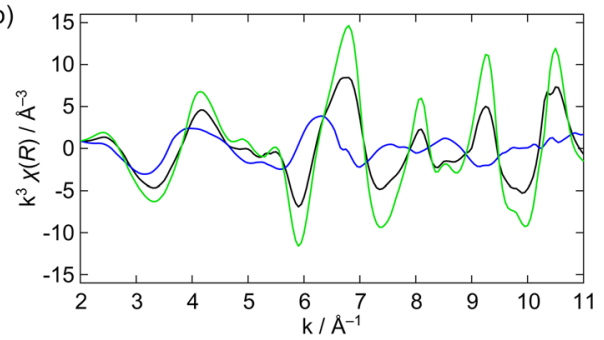

(c)

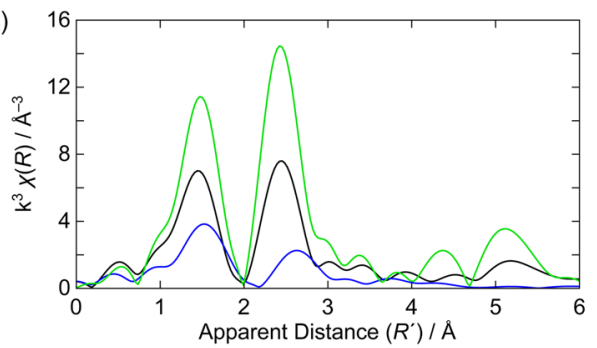

Fig. 3 X-ray absorbance spectra of $\mathbf{C o F e O}_{\boldsymbol{x}}$ a Fe K-edge X-ray absorbance spectra and corresponding $\mathbf{b} \mathrm{k}$-space and $\mathbf{c} \mathrm{R}$-space for $\mathrm{CoFeO}_{x}$ with the composition 50\% Fe:50\% Co (black line), and calculated $\mathrm{Fe}^{3+}$ (blue line) and $\mathrm{Fe}^{4+}$ spectra (green line). Inset of a highlights the pre-edge region.

structure (XANES) spectra and the k-space and R-space data are given in Fig. 3 for $\mathrm{CoFeO}_{x}$ with a $50 \% \mathrm{Fe}: 50 \%$ Co (black line) composition. Analogous data for several other compositions are given in Supplementary Fig. 8. As the proportions of $\mathrm{Fe}^{3+}$ and $\mathrm{Fe}^{4+}$ are known from Mössbauer, the individual XANES spectrum for each $\mathrm{Fe}^{3+} / \mathrm{Fe}^{4+}$ species may be ascertained from linear combination fitting. The resulting $\mathrm{Fe}^{3+}$ and $\mathrm{Fe}^{4+}$ spectra are reproducible for specific linear combinations (Supplementary Figs. 9 and 10); the spectrum for the 50\% Fe:50\% Co sample (black line) and corresponding linear combinations for the $\mathrm{Fe}^{3+}$ and $\mathrm{Fe}^{4+}$ (blue and green line, respectively) contributions are given in Fig. 3. Several important observations can be made between the $\mathrm{Fe}^{3+}$ and $\mathrm{Fe}^{4+}$ species. There is a large edge shift from $\sim 7124$ to $\sim 7128 \mathrm{eV}$ between the $\mathrm{Fe}^{3+}$ and $\mathrm{Fe}^{4+}$ species. Additionally, the $1 s \rightarrow 3 d$ pre-edge intensity of the $\mathrm{Fe}^{3+}$ species is significantly higher than that for $\mathrm{Fe}^{4+}$ (inset of Fig. 3a). The Rspace amplitude of the $\mathrm{Fe}^{3+}$ species is significantly lower than the $\mathrm{Fe}^{4+}$ species (Fig. 3c). This decreased amplitude suggests a lower coordination number. There is also a clear contraction of the first and second shell scattering distances for $\mathrm{Fe}^{4+}$. The pre-edge region reflects transitions to the many-electron excited states of the metal centre. The spectral intensity of the pre-edge derives from both electric quadrupole and electric dipole mechanisms. In a centrosymmetric ligand field (e.g., $O_{h}$ ), the electric dipole contribution is parity forbidden, and only the quadrupole intensity is present. Conversely, deviation from centrosymmetry (e.g., $T_{d}$ ) results in a significant increase in the pre-edge intensity. This increase in intensity derives from electric dipole allowedness, which tracks with the amount of $3 d-4 p$ mixing in a noncentrosymmetric ligand field ${ }^{73}$. These observations, together with a low coordination number from the low amplitude R-space data, suggest that $\mathrm{Fe}^{3+}$ is present in a distorted ligand field lacking inversion symmetry-either $T_{d}$ or square pyramidal ligand field geometries are likely possiblities. ${ }^{73}$ Along similar lines for $\mathrm{Fe}^{4+}$, the low pre-edge intensity suggests a more symmetric $O_{h}$ ligand field, which will largely exhibit electric quadrupole intensity. A more symmetric ligand field is also consistent with the higher amplitude R-space data and small $\left|\Delta E_{\mathrm{Q}}\right|$.

The combination of Mössbauer, XAS, and EXAFS data support the assignment of a high-valent $\mathrm{Fe}^{4+}$ species in a symmetric $O_{h}$ ligand field. An alternative scenario to consider is a low-spin $\mathrm{Fe}^{3+}$ centre, though it must be in a strongly electron withdrawing environment. For instance, negative isomer shifts can be obtained in low-spin $\mathrm{Fe}^{3+}$ complexes in the presence of strong backbonding (e.g., $\mathrm{K}_{3}\left[\mathrm{Fe}^{3+}(\mathrm{CN})_{6}\right]$ or $\left.\mathrm{Na}_{2}\left[\mathrm{Fe}^{3+}(\mathrm{CN})_{5} \mathrm{NO}\right]\right)^{74}$. Additionally, when $\left[\mathrm{Fe}^{3+}(\mathrm{CN})_{6}\right]^{3-}$ is coordinated in supramolecular assemblies (e.g., Prussian blue analogues) involving metal-metal interactions. Such second-sphere coordination of the $\mathrm{Fe}-\mathrm{CN}$ bonds by another metal ion can shift the Fe $\delta$ by $\sim-0.1 \mathrm{~mm} / \mathrm{s}$. Thus, metal-metal or charge transfer interactions in $\mathrm{CoFeO}_{x}$ could effectively decrease the Fe-based $s$ electron density and give rise to a negative $\delta$ and high Fe K-edge energy. However, this scenario would result in an isomer shift that gradually shifts more negative as this Fe species is surrounded by more Co centres. This is not observed here; the isomer shift of the Fe species remains relatively constant at $\delta \sim-0.2 \mathrm{~mm} / \mathrm{s}$ and in fact becomes slightly less negative with increasing Co concentration (Supplementary Fig. 7). Similarly, the $\mathrm{Fe}^{4+}$ XAS spectra obtained from linear combination fits using different Co:Fe ratios are very similar (Supplementary Fig. 9). These considerations, together with the weak ligand field imposed by oxide coordination and the consistency between the Mössbauer and Fe K-edge XAS data, suggest that the Fe species observed here can be assigned to a high-valent $\mathrm{Fe}^{4+}$ centre in an $\mathrm{O}_{h}$ ligand field.

\section{Discussion}

Iron activates M-OECs for OER but its role appears to differ with the nature of the M-OEC and the condition under which it operates. Although most OER is performed in concentrated base, the large-scale deployment of renewable energy storage has prompted interest in performing OER in neutral water sources $^{75,76}$. For this line of investigation, M-OECs excel owing to their stability arising from their self-healing properties ${ }^{22}$. At neutral $\mathrm{pHs}, \mathrm{Fe}^{3+}$ plays a role in OER that appears to be derived 
from non-redox properties. PCET activation of water is impaired since water is a poor proton acceptor; Fe may act as a Lewis acid ${ }^{77}$ to increase the acidity of $\mathrm{OH}_{x}$ (aqua/hydroxo) moieties that are coordinated to M-OECs and thereby lower the reduction potential for the $\mathrm{M}^{3+/ 4+}$ couple and lead to a greater population of $\mathrm{M}^{4+}$ in the $\mathrm{Fe}$-doped catalysts. This in turn gives rise to increased oxyl character (M(IV) $\left.\ldots \mathrm{O} \leftrightarrow \mathrm{M}(\mathrm{III})-\mathrm{O}^{\bullet}\right)$. This Lewis acidity behaviour is supported by the observation that Fe doping in $\mathrm{NiPbO}_{x}$ shows no enhancement in OER at solution $\mathrm{pH}$ values commensurate with the $\mathrm{p} K_{\mathrm{a}}$ of $\mathrm{Fe}^{3+}$. Moreover, OER enhancement may be replicated by non-redox active, Lewis acidic cations in $\mathrm{Fe}$-free $\mathrm{Ni}$-OECs ${ }^{78}$. In concentrated base, $\mathrm{OH}^{-}$can adequately serve the role of a proton acceptor and the influence of the $\mathrm{Fe}^{3+}$ is diminished. When $\mathrm{Fe}^{4+}$ is implicated in OER, as has been proposed in numerous studies, OER appears to occur at the M (Co or $\mathrm{Ni}$ ) metal centre with $\mathrm{Fe}^{4+}$ promoting the activation of OER at the $\mathrm{M}$ of the M-OEC. Such proposals are consistent with the electronic structure of first row transition metal centres confronting the "oxo-wall"79. Moving to the right in the periodic table, the $d$-electron count for the $\mathrm{M}^{4+}$ formal oxidation state increases and in a tetragonal oxide ligand field, the $d_{\mathrm{xz}}$ and $d_{\mathrm{yz}}$ orbitals are populated, preventing electron donation from terminal oxygen to the metal centre. Consequently, the $\mathrm{M}-\mathrm{O}$ bond strength is much weaker for $\mathrm{Co}^{4+}$ than for $\mathrm{Fe}^{4+}$, which formally accommodates a kinetically more inert metal-oxo double bond. From a kinetics perspective, we believe that $\mathrm{Fe}^{4+}$ is not the active site from which OER occurs but rather OER occurs from Co centres with the $\mathrm{Fe}^{4+}$ participating as a redox cooperative centre where $\mathrm{Fe}^{4+}$ enhances the oxidizing power of a Co:Fe active site (Supplementary Fig. 1) versus a $\mathrm{Co}^{4+}$-only active site. Thus, we believe that for both $\mathrm{NiFeO}_{x}$ and $\mathrm{CoFeO}_{x}$ systems, $\mathrm{Fe}^{3+}$ functions as a Lewis acid in promoting PCET reactivity for the OER. However, unlike $\mathrm{NiFeO}_{x}$, OER activity in $\mathrm{CoFeO}_{x}$ tracks the $\mathrm{Fe}^{4+}$ alloying concentration, suggesting that the redox properties of the $\mathrm{Co}^{4+}$ centre is further enhanced by the presence of redox active $\mathrm{Fe}^{4+}$ centres.

In conclusion, we have spectroscopically detected and characterized a high-valent $\mathrm{Fe}^{4+}$ centre in $\mathrm{CoFeO}_{x}$ thin film OECs. Spectroscopic data suggest that this $\mathrm{Fe}^{4+}$ centre is located in a symmetric $\mathrm{O}_{h}$ oxide ligand field. The correlation between $\mathrm{Fe}^{4+}$ content and OER activity in $\mathrm{CoFeO}_{x}$ thin films suggests an important role of this high-valent state in the mechanism of $\mathrm{O}-\mathrm{O}$ bond formation and oxygen evolution and supports the merits of exploring mixed-metallate oxygen evolution catalysts.

\begin{abstract}
Methods
Materials. Catalysts with specific Fe:Co ratios were prepared by electrodeposition from metal nitrate salt solutions that were degassed. After deposition, the film was rinsed briefly in Type I water and then submerged in $\mathrm{KOH}$ buffer. Films were held at a constant potential of $0.84 \mathrm{~V}$ in $1 \mathrm{M} \mathrm{KOH} \mathrm{pH} 14$ or $1.0 \mathrm{~V}$ in $0.1 \mathrm{M} \mathrm{KOH}$ $\mathrm{pH} 13$ for $3 \mathrm{~h}$ to convert the film to the oxyhydroxide form before further electrochemical analysis. To obtain films of various thicknesses, the total deposition time was altered between 30 and $120 \mathrm{~s}$ and the current held during deposition was changed between $0.5,1.0$ and $5.0 \mathrm{~mA} / \mathrm{s}$. The exact film loading was obtained from ICP-MS analysis of the films.
\end{abstract}

Electrochemistry. All electrochemical experiments were conducted at room temperature $\left(23 \pm 1^{\circ} \mathrm{C}\right)$. Electrode potentials were converted to the NHE scale using $E(\mathrm{NHE})=E(\mathrm{Ag} / \mathrm{AgCl})+0.197 \mathrm{~V}$. Overpotentials for the OER from water were computed using $\eta=E(\mathrm{NHE})-(1.23 \mathrm{~V}-0.059 \mathrm{~V} \times \mathrm{pH})$.

Spectroscopy. $\mathrm{CoFeO}_{\mathrm{x}}$ catalyst with natural ${ }^{57} \mathrm{Fe}$ abundance were prepared for Mössbauer spectroscopy at $77 \mathrm{~K}$. The data were calibrated and fit to linear combinations of symmetric pairs of Lorentzian peaks. Fe K-edge XANES spectra were collected at beamline 12BM-B at the Advanced Photon Source at Argonne National Laboratory. Reconstructed spectra of the pure $\mathrm{Fe}^{3+}$ and $\mathrm{Fe}^{4+}$ species were obtained through linear combinations of the XAS spectra of the various $\mathrm{CoFeO}_{x}$ films.

\section{Data availability}

Experimental procedures, characterization of compounds electrochemical and spectral data are available in the Supplementary Information. All data are available from the authors on reasonable request.

Received: 27 February 2021; Accepted: 15 June 2021; Published online: 09 July 2021

\section{References}

1. Kanan, M., Surendranath, Y. \& Nocera, D. G. Cobalt-phosphate oxygenevolving compound. Chem. Soc. Rev. 38, 109-114 (2009).

2. Bediako, D. K., Ullman, A. M. \& Nocera, D. G. Catalytic oxygen evolution by cobalt oxido thin films. Top. Curr. Chem. 371, 173-214 (2016).

3. Surendranath, Y. \& Nocera, D. G. Oxygen evolution reaction chemistry of oxide-based electrodes. Prog. Inorg. Chem. 57, 505-560 (2011).

4. Suen, N.-T. et al. Electrocatalysis for the oxygen evolution reaction: recent development and future perspectives. Chem. Soc. Rev. 46, 337-365 (2017).

5. Roger, I., Shipman, M. A. \& Symes, M. D. Earth-abundant catalysts for electrochemical and photoelectrochemical water splitting. Nat. Rev. Chem. 1, 0003 (2017).

6. Kanan, M. W. \& Nocera, D. G. In situ formation of an oxygen-evolving catalyst in neutral water containing phosphate and $\mathrm{Co}^{2+}$. Science 321 , 1072-1075 (2008)

7. Surendranath, Y., Dincă, M. \& Nocera, D. G. Electrolyte-dependent electrosynthesis and activity of cobalt based water oxidation catalysts. J. Am. Chem. Soc. 131, 2615-2620 (2009).

8. Esswein, A. S., Surendranath, Y., Reece, S. Y. \& Nocera, D. G. Highly active cobalt phosphate and borate based oxygen evolving anodes operating in neutral and natural waters. Energy Environ. Sci. 4, 499-504 (2011).

9. Farrow, C. L., Bediako, D. K., Surendranath, Y., Nocera, D. G. \& Billinge, S. J. L. Intermediate-range structure of self-assembled cobalt-based oxygen evolving catalysts. J. Am. Chem. Soc. 135, 6403-6406 (2103).

10. Dincă, M., Surendranath, Y. \& Nocera, D. G. A nickel-borate oxygen evolving catalyst that functions under benign conditions. Proc. Natl Acad. Sci. USA 107, 10337-10341 (2010)

11. Bediako, D. K., Surendranath, Y. \& Nocera, D. G. Mechanistic studies of the oxygen evolution reaction mediated by a nickel-borate thin film electrocatalyst. J. Am. Chem. Soc. 135, 3662-3674 (2013).

12. Huynh, M., Bediako, D. K., Liu, Y. \& Nocera, D. G. Nucleation and growth mechanisms of an electrodeposited manganese oxide oxygen evolution catalyst. J. Phys. Chem. C 118, 17142-17152 (2014).

13. Huynh, M., Bediako, D. K. \& Nocera, D. G. A functionally stable manganese oxide oxygen evolution catalyst in acid. J. Am. Chem. Soc. 136, 6002-6010 (2014).

14. Bediako, D. K. et al. Structure-activity correlations in a nickel-borate oxygen evolution catalyst. J. Am. Chem. Soc. 134, 6801-6809 (2012).

15. Liu, Y. \& Nocera, D. G. Spectroscopic studies of nanoparticulate thin films of a cobalt-based oxygen evolution catalyst. J. Phys. Chem. C 118, 17060-17066 (2014).

16. Du, P., Kikhan, O., Chapman, K., Chupas, P. \& Tiede, D. Elucidating the domain structure of the cobalt oxide water splitting catalyst by $\mathrm{x}$-ray pair distribution function analysis. J. Am. Chem. Soc. 134, 11096-11099 (2012)

17. Huynh, M., Shi, C., Billinge, S. J. L. \& Nocera, D. G. Nature of activated manganese oxide for oxygen evolution. J. Am. Chem. Soc. 137, 14887-14904 (2015).

18. Kwon, G. et al. Resolution of electronic and structural factors underlying oxygen-evolving performance in amorphous cobalt oxide catalysts. J. Am. Chem. Soc. 140, 10710-10720 (2018).

19. Kanan, M. W. et al. Structure and valency of a cobalt-phosphate water oxidation catalyst determined by in situ x-ray spectroscopy. J. Am. Chem. Soc 132, 13692-13701 (2010)

20. Lutterman, D. A., Surendranath, Y. \& Nocera, D. G. A self-healing oxygenevolving catalyst. J. Am. Chem. Soc. 131, 3838-3839 (2009).

21. Surendranath, Y., Lutterman, D. A., Liu, Y. \& Nocera, D. G. Nucleation, growth, and repair of a cobalt-based oxygen evolving catalyst. J. Am. Chem. Soc. 134, 6326-6336 (2012).

22. Costentin, C. \& Nocera, D. G. Self-healing catalysis in water. Proc. Natl Acad. Sci. USA 114, 13380-13384 (2017).

23. Reece, S. Y. et al. Wireless solar water splitting using silicon-based semiconductors and earth abundant catalysts. Science 334, 645-648 (2011).

24. Pijpers, J. J. H., Winkler, M. T., Surendranath, Y., Buonassisi, T. \& Nocera, D. G. Light-induced water oxidation at silicon electrodes functionalized with a cobalt oxygen evolving catalyst. Proc. Natl Acad. Sci. USA 108, 10056-10061 (2011).

25. Nocera, D. G. Artificial leaf. Acc. Chem. Res. 45, 767-776 (2012). 
26. Cox, C. R., Lee, J. Z., Nocera, D. G. \& Buonassisi, T. Ten percent solar-to-fuel conversion with non-precious materials. Proc. Natl Acad. Sci. USA 111, 14057-14061 (2014).

27. Torella, J. P. et al. Efficient solar-to-fuels production from a hybrid microbial water splitting catalyst system. Proc. Natl Acad. Sci. USA 112, 2337-2332 (2015).

28. Liu, C., Colón, B. C., Ziesack, M., Silver, P. A. \& Nocera, D. G. Water splittingbiosynthetic system with $\mathrm{CO}_{2}$ reduction efficiencies exceeding photosynthesis. Science 352, 1210-1213 (2016).

29. Dogutan, D. K. \& Nocera, D. G. Artificial photosynthesis at efficiencies greatly exceeding that of natural photosynthesis. Acc. Chem. Res. 52, 3143-3148 (2019).

30. Ullman, A. M., Brodsky, C. N., Li, N., Zheng, S.-L. \& Nocera, D. G. Probing edge site reactivity of oxidic cobalt water oxidation catalysts. J. Am. Chem. Soc. 138, 4229-4236 (2016).

31. Surendranath, Y., Kanan, M. W. \& Nocera, D. G. Mechanistic studies of the oxygen evolution reaction by a cobalt-phosphate catalyst at neutral pH. J. Am. Chem. Soc. 132, 16501-16509 (2010).

32. Mattioli, G. et al. Reaction pathways for oxygen evolution promoted by cobalt catalyst. J. Am. Chem. Soc. 135, 15353-15363 (2013).

33. García-Mota, M. et al. Importance of correlation in determining electrocatalytic oxygen evolution activity on cobalt oxides. J. Phys. Chem. C 116, 21077-21088 (2012)

34. Friebel, D. et al. On the chemical state of Co oxide electrocatalysts during alkaline water splitting. Phys. Chem. Chem. Phys. 15, 17460-17467 (2013).

35. Chen, J. \& Selloni, A. First principles study of cobalt (hydr)oxides under electrochemical conditions. J. Phys. Chem. C 117, 20002-20006 (2013).

36. Kim, H. et al. Coordination tuning of cobalt phosphates towards efficient water oxidation catalyst. Nat. Commun. 6, 8253 (2015).

37. Hadt, R. G. et al. X- ray spectroscopic characterization of $\mathrm{Co}(\mathrm{IV})$ and metalmetal interactions in $\mathrm{Co}_{4} \mathrm{O}_{4}$ : electronic structure contributions to the formation of high-valent states relevant to the oxygen evolution reaction. $J$. Am. Chem. Soc. 138, 11017-11030 (2016).

38. Brodsky, C. N. et al. In situ characterization of cofacial Co(IV) centers in a $\mathrm{Co}_{4} \mathrm{O}_{4}$ cubane: modeling the high-valent active site in oxygen evolving catalysts. Proc. Natl Acad. Sci. USA 114, 3855-3860 (2017).

39. Bediako, D. K., Costentin, C., Jones, E. C., Nocera, D. G. \& Savéant, J.-M. Proton-electron transport and transfer in electrocatalytic films. Application to a cobalt-based $\mathrm{O}_{2}$-evolution catalyst. J. Am. Chem. Soc. 135, 10492-10502 (2013).

40. Costentin, C. \& Nocera, D. G. Dual-phase molecular-like charge transport in nanoporous transition metal oxides. J. Phys. Chem. C 123, 1966-1973 (2019).

41. Bediako, D. K. et al. Proton-electron conductivity in thin films of a cobaltoxygen evolving catalyst. C. N. Brodsky. ACS Appl. Energy Mater. 2, 3-12 (2019).

42. Corrigan, D. A. The catalysis of the oxygen evolution reaction by iron impurities in thin film nickel oxide electrodes. J. Electrochem. Soc. 134, 377-384 (1987).

43. Corrigan, D. A. \& Bendert, R. M. Effect of coprecipitated metal ions on the electrochemistry of nickel hydroxide thin films: cyclic voltammetry in $1 \mathrm{M}$ KOH. J. Electrochem. Soc. 136, 723-728 (1989).

44. Trotochaud, L., Ranney, J. K., Williams, K. N. \& Boettcher, S. W. Solution-cast metal oxide thin film electrocatalysts for oxygen evolution. J. Am. Chem. Soc. 134, 17253-17261 (2012).

45. Friebel, D. et al. Identification of highly active Fe sites in (Ni,Fe)OOH for electrocatalytic water splitting. J. Am. Chem. Soc. 137, 1305-1313 (2015).

46. Swierk, J. R., Klaus, S., Trotochaud, L., Bell, A. T. \& Tilley, T. D. Electrochemical study of the energetics of the oxygen evolution reaction at nickel iron (oxy)hydroxide catalysts. J. Am. Chem. Soc. 119, 19022-19029 (2015).

47. Martirez, J. M. P. \& Carter, E. A. Unraveling oxygen evolution on iron-doped beta-nickel oxyhydroxide: the key role of highly active molecular-like sites. $J$. Am. Chem. Soc. 141, 693-705 (2019).

48. Klaus, S., Cai, Y., Louie, M. W., Trotochaud, L. \& Bell, A. T. Effects of Fe electrolyte impurities on $\mathrm{Ni}(\mathrm{OH})_{2} / \mathrm{NiOOH}$ structure and oxygen evolution activity. J. Phys. Chem. C 119, 7243-7254 (2015).

49. Smith, R. D. L. et al. Geometric distortions in nickel (oxy)hydroxide electrocatalysts by redox inactive iron ions. Energy Environ. Sci. 11, 2476-2485 (2018).

50. Alsaç, E. P., Whittingham, A., Liu, Y. \& Smith, R. D. L. Probing the role of internalized geometric strain on heterogeneous electrocatalysis. Chem. Mater. 31, 7522-7530 (2019).

51. Lee, S., Bai, L. \& Hu, X. Deciphering iron-dependent activity in oxygen evolution catalyzed by nickel-iron layered double hydroxide. Angew. Chem. Int. Ed. 59, 8072-8079 (2020).

52. Lee, S., Banjac, K., Lingenfelder, M. \& Hu, X. Oxygen isotope labeling experiments reveal different reaction sites for the oxygen evolution reaction on nickel and nickel iron oxides. Angew. Chem. Int. Ed. 58, 10295-10299 (2019).
53. Shin, H., Xiao, H. \& Goddard, W. A. III Synergy between Fe and Ni in the optimal performance of $(\mathrm{Ni}, \mathrm{Fe}) \mathrm{OOH}$ catalysts for the oxygen evolution reaction. Proc. Natl Acad. Sci. USA 115, 5872-5877 (2018).

54. Shin, H., Xiao, H. \& Goddard, W. A. III In silico discovery of new dopants for Fe-doped $\mathrm{Ni}$ oxyhydroxide $\left(\mathrm{Ni}_{1-\mathrm{x}} \mathrm{Fe}_{\mathrm{x}} \mathrm{OOH}\right)$ catalysts for oxygen evolution reaction. J. Am. Chem. Soc. 140, 6745-6748 (2018).

55. Louie, M. W. \& Bell, A. T. An investigation of thin-film Ni-Fe oxide catalysts for the electrochemical evolution of oxygen. J. Am. Chem. Soc. 135, 12329-12337 (2013)

56. Trotochaud, L., Young, S. L., Ranney, J. K. \& Boettcher, S. W. Nickel-iron oxyhydroxide oxygen-evolution electrocatalysts: the role of intentional and incidental iron incorporation. J. Am. Chem. Soc. 136, 6744-6753 (2014).

57. $\mathrm{Li}, \mathrm{N}$. et al. Influence of iron doping on tetravalent nickel content in catalytic oxygen evolving films. Proc. Natl Acad. Sci. USA 114, 1486-1491 (2017)

58. Li, N. et al. Template-stabilized oxidic nickel oxygen evolution catalysts. Proc. Natl Acad. Sci. USA 117, 16187-16192 (2020).

59. Chen, J. Y. C. et al. Operando analysis of NiFe and Fe oxyhydroxide electrocatalysts for water oxidation: detection of $\mathrm{Fe}^{4+}$ by Mössbauer spectroscopy. J. Am. Chem. Soc. 137, 15090-155093 (2015).

60. Xiao, C., Lu, X. \& Zhao, C. Unusual synergistic effects upon incorporation of $\mathrm{Fe}$ and/or $\mathrm{Ni}$ into mesoporous $\mathrm{Co}_{3} \mathrm{O}_{4}$ for enhanced oxygen evolution. Chem. Commun. 50, 10122-10125 (2014).

61. Burke, M. S., Kast, M. G., Trotochaud, L., Smith, A. M. \& Boettcher, S. W. Cobalt-iron (oxy)hydroxide oxygen evolution electrocatalysts: the role of structure and composition on activity, stability, and mechanism. J. Am. Chem. Soc. 137, 3638-3648 (2015).

62. Smith, R. D. L. et al. Spectroscopic identification of active sites for the oxygen evolution reaction on iron-cobalt oxides. Nat. Commun. 8, 2022 (2017).

63. Li, N., Keane, T. P., Veroneau, S. S. \& Nocera, D. G. Role of electrolyte composition on the acid stability of mixed-metal oxygen evolution catalysts. Chem. Commun. 56, 10477-10480 (2020).

64. Pollard, R. J. On the Mössbauer spectrum of $\gamma-\mathrm{Fe}_{2} \mathrm{O}_{3}$. Hyperfine Interact. 41, 509-512 (1988).

65. Pankhurst, Q. A., Johnson, C. E. \& Thomas, M. F. A Mossbauer study of magnetic phase transitions in alpha- $\mathrm{Fe}_{2} \mathrm{O}_{3}$ crystals. J. Phys. C 19, 7081-7098 (1986).

66. Niemantsverdrlet, J. W., van der Kraan, A. M., van Dijk, W. L. \& van der Baan, H. S. Behavior of metallic iron catalysts during Fischer-Tropsch synthesis studied with Mössbauer spectroscopy, x-ray diffraction, carbon content determination, and reaction kinetic measurements. J. Phys. Chem. 84, 3363-3370 (1980).

67. Preston, R. S. \& Hanna, S. S. Mössbauer effect in metallic iron. J. Phys. Rev. 128, 2207-2218 (1962).

68. Demourgues-Guerlou, L., Fournès, L. \& Delmas, C. In situ ${ }^{57} \mathrm{Fe}$ Mössbauer spectroscopy study of the electrochemical behavior of an iron-substituted nickel hydroxide electrode. J. Electrochem. Soc. 143, 3083-3088 (1996)

69. Corrigan, D. A., Conell, R. S., Fierro, C. A. \& Scherson, D. A. In-situ Moessbauer study of redox processes in a composite hydroxide of iron and nickel. J. Phys. Chem. 91, 5009-5011 (1987).

70. O'Grady, W. E. Mössbauer study of the passive oxide film on iron. J. Electrochem. Soc. 127, 555-563 (1980).

71. Conesa, J. C. Electronic structure of the (undoped and Fe-doped) $\mathrm{NiOOH} \mathrm{O}$ evolution electrocatalyst. J. Phys. Chem. C 120, 18999-19010 (2016).

72. Subbaraman, R. et al. Trends in activity for the water electrolyser reactions on 3d M(Ni,Co,Fe,Mn) hydr(oxy)oxide catalysts. Nat. Mater. 11, 550-557 (2012).

73. Westre, T. E. et al. A multiplet analysis of Fe K-edge $1 \mathrm{~s} \rightarrow 3 \mathrm{~d}$ pre-edge features of iron complexes. J. Am. Chem. Soc. 119, 6297-6314 (1997).

74. Chandra, K., Raj, D. \& Puri, S. P. Mössbauer studies of ferro- and ferricyanide supercomplexes with $3 \mathrm{~d}$ transition elements. J. Chem. Phys. 46, 1466-1468 (1967).

75. Tong, W. et al. Electrolysis of low-grade and saline surface water. Nat. Energy 5, 367-377 (2020).

76. Dresp, S., Dionigi, F., Klingenhof, M. \& Strasser, P. Direct electrolytic splitting of seawater: opportunities and challenges. ACS Energy Lett. 4, 933-942 (2019).

77. Jerome, S. V., Hughes, T. F. \& Friesner, R. A. Accurate $\mathrm{pK}_{\mathrm{a}}$ prediction in firstrow hexaaqua transition metal complexes using the B3LYP-DBLOC method. J. Phys. Chem. B 118, 8008-8016 (2014).

78. Garcia, A. C., Touzalin, T., Nieuwland, C., Perini, N. \& Koper, M. T. M. Enhancement of oxygen evolution activity of nickel oxyhydroxide by electrolyte alkali cations. Angew. Chem. Int. Ed. 58, 12999-13003 (2019).

79. Winkler, J. R. \& Gray, H. B. in Structure and Bonding (eds. Mingos, D. M. P. et al.) Vol. 142, 17-28 (Springer, 2012).

\section{Acknowledgements}

Material is based upon work supported under the Solar Photochemistry Program of the Chemical Sciences, Geosciences and Biosciences Division, Office of Basic Energy Sciences of the U.S. Department of Energy DE-SC0017619. 


\section{Author contributions}

N.L., R.G.H., and D.H. conducted the experiments. N.L., R.G.H., D.H., L.X.C., and

D.G.N. designed experiments and analysed and interpreted the data. D.G.N. prepared

a draft of the manuscript and finalized the manuscript.

\section{Competing interests}

The authors declare no competing interests.

\section{Additional information}

Supplementary information The online version contains supplementary material available at https://doi.org/10.1038/s41467-021-24453-6.

Correspondence and requests for materials should be addressed to R.G.H., D.H. or D.G.N.

Peer review information Nature Communications thanks the anonymous reviewers for their contribution to the peer review of this work.
Reprints and permission information is available at http://www.nature.com/reprints

Publisher's note Springer Nature remains neutral with regard to jurisdictional claims in published maps and institutional affiliations.

(C) The Author(s) 2021 redit to the original author(s) and the source, provide a link to the Creative Commons license, and indicate if changes were made. The images or other third party material in this article are included in the article's Creative Commons license, unless indicated otherwise in a credit line to the material. If material is not included in the article's Creative Commons license and your intended use is not permitted by statutory regulation or exceeds the permitted use, you will need to obtain permission directly from the copyright holder. To view a copy of this license, visit http://creativecommons.org/licenses/by/4.0/. 